\title{
Performance Evaluation of Stepped Spillway under Nappe Flow Condition
}

\author{
Patil L.G. ${ }^{1}$, Jadhav S.S. ${ }^{2}$ \\ Associate Professor, Department of Civil Engineering, SGGSIE\&T, Nanded, India ${ }^{1}$ \\ M. Tech Student, Department of Civil Engineering, SGGSIE\&T, Nanded, India ${ }^{2}$
}

\begin{abstract}
A stepped spillway is a spillway with steps on the spillway chute to assist in the dissipation of the kinetic energy of the descending water. This reduces size or eliminates the need for an additional energy dissipator on downstream side. The energy dissipation depends upon the step height and discharge. In this study effect of number of steps and discharge on energy dissipation were studied using computational fluid dynamics (CFD) approach. Effect of number of steps and discharge was evaluated for nappe flow conditions. This study shows that as number of steps are increased the energy dissipation decreases and also increase in discharge results in the decrease in energy dissipation under nappe flow.
\end{abstract}

Keywords: Mean Kinetic Energy, Energy Dissipation, CFD, Number of steps and Discharge.

\section{INTRODUCTION}

In modern times due to the use RCC dams and prefabricated blocs, stepped spillways are becoming more popular especially for small dams. Stepped spillway reduce the need of large energy dissipaters at the toe of the spillway.The flow over a stepped spillway may be divided into three flow regimes namely nappe, skimming and transition depending upon the flow rate for a given stepped spillway geometry. Nappe flow dissipate maximum energy for small size stepped spillway and skimming flow dissipate the maximum energy for large size stepped spillway. The energy dissipation on stepped spillway depends upon number of steps, step height, step length and discharge. In this study effect of number of steps and discharge on energy dissipation under nappe flow condition were studied using CFD approach.

\section{LITERATURE REVIEW}

In the recent past, many researchers have conducted both experimental and numerical investigation on stepped spillway.

\section{Nappe flow occurrence:}

Chanson equation (Khatsuria (9)) gives condition for upper limit of nappe flow regimes as

$\frac{\mathrm{y}_{\mathrm{c}}}{\mathrm{h}}=0.89-0.4(\mathrm{~h} / \mathrm{l})$

It is valid for uniform flow or quasi-uniform flow (not rapidly varied flow) and within the range $0.05 \leq(\mathrm{h} / \mathrm{l}) \leq$ 1.7.

Where, $y_{c}=$ critical depth of flow, $h=$ height of step,l= step length.

The upper limit of nappe flow given by Chinnarasri equation as: $\frac{y_{c}}{h}=0.98(0.55)^{h / 1}$

The lower limit of the step height for the formation of nappe flow has given Yasuda as follows.

$\frac{\mathrm{h}}{\mathrm{y}_{\mathrm{c}}}=0.57(\mathrm{~h} / \mathrm{l})^{3}+1.3$

for $0.1 \leq(h / l) \leq 1.43$ and $0<\left(h / y_{c}\right) \leq 1.37$

Chanson equation (Khatsuria (9)) present conditions for the occurrence of isolated nappe flow with a fully developed hydraulic jump, for interval $0.2 \leq \mathrm{h} / 1 \leq 0.6$. as

$\frac{y_{c}}{h}=0.0916(h / l)^{-1.276}$

As discharge or chute slope increases, the hydraulic jump will not form.

\section{Energy dissipation:}

Chanson equation (Khatsuria (9)) for calculation of residual head is as follows:

$\frac{\mathrm{H}_{\mathrm{r}}}{\mathrm{H}_{\max }}=\frac{0.54\left(\frac{\mathrm{yc}}{\mathrm{h}}\right)^{0.275}+1.715\left(\frac{\mathrm{yc}}{\mathrm{h}}\right)^{-0.55}}{1.5+\left(\frac{\mathrm{H}_{\mathrm{d}}}{\mathrm{y}_{\mathrm{c}}}\right)}$

Where, $\mathrm{H}_{\mathrm{r}}=$ residual head, immediately downstream of the channel, $\mathrm{H}_{\max }=$ maximum head, $\mathrm{H}_{\mathrm{d}}=$ Dam height from the toe up to the spillway crest. It is valid for free flow spillways and nappe flow with fully developed hydraulic jump.

Rao and Rao (11) investigated the effect of number of steps on energy dissipation using experimental approach. Result indicates that the effect of number of $\operatorname{steps}(\mathrm{N})$ appears negligible on energy dissipation at $\mathrm{y}_{\mathrm{c}} / \mathrm{h}=0.2$ and 
Vol. 4, Issue 1, January 2017

effect of $\mathrm{N}$ is prominent on energy dissipation at high $\mathrm{y}_{\mathrm{c}} / \mathrm{h}$ ratio.

Roshan et.al (12) experimentally investigates the effect of number of steps on energy dissipation. Result shows that increasing number of steps leads the decrease in energy dissipation.

Stefan and Hubert (13) investigated the effect of non uniform step height on energy dissipation. Result of investigation shows that energy dissipation is same for uniform and non uniform step height stepped spillway.

Rasul et.al (10) experimentally investigated the effect of number of steps and discharge on energy dissipation under semicircular crest stepped spillway and traditional spillway. Result of investigation shows that increasing number of steps and discharge leads to decreasing the energy dissipation.

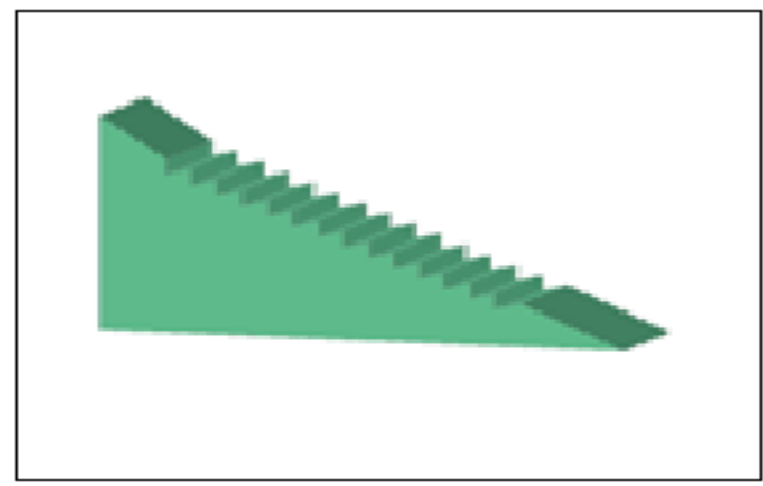

Fig.1 stepped spillway

\section{NUMERICAL MODEL}

The geometry consists of stepped spillway with different number of steps (7, 8 and 10) which are shown in fig.2, fig. 3 and fig.4. The computational grids are generated in the Autodesk Inventor. Eight different discharges (0.001, $0.002,0.003,0.004,0.005,0.006,0.007,0.008 \mathrm{~m}^{3} / \mathrm{s}$ ) were considered for the study. Dimensions of model are $0.24 \mathrm{~m}$ width, $0.49 \mathrm{~m}$ height. Width and height of model are kept constant throughout the study. For all the discharges and step height considered in this study, the flow over stepped was found to be nappe.

\section{TABLE 1 RANGE OF VARIABLE FOR PRESENT STUDY}

\begin{tabular}{|c|c|c|c|}
\hline Number of steps & $\mathbf{7}$ & $\mathbf{8}$ & $\mathbf{1 0}$ \\
\hline \multirow{4}{*}{$\begin{array}{c}\text { Inflow } \\
\text { Discharge } \\
\left.\text { ( } \mathbf{m}^{\mathbf{3}} / \mathbf{s}\right)\end{array}$} & 0.001 & 0.001 & 0.001 \\
\cline { 2 - 4 } & 0.002 & 0.002 & 0.002 \\
\cline { 2 - 4 } & 0.003 & 0.003 & 0.003 \\
\cline { 2 - 4 } & 0.004 & 0.004 & 0.004 \\
\cline { 2 - 4 } & 0.005 & 0.005 & 0.005 \\
\cline { 2 - 4 } & 0.006 & 0.006 & 0.006 \\
\cline { 2 - 4 } & 0.007 & 0.007 & 0.007 \\
\cline { 2 - 4 } & 0.008 & 0.008 & 0.008 \\
\hline
\end{tabular}

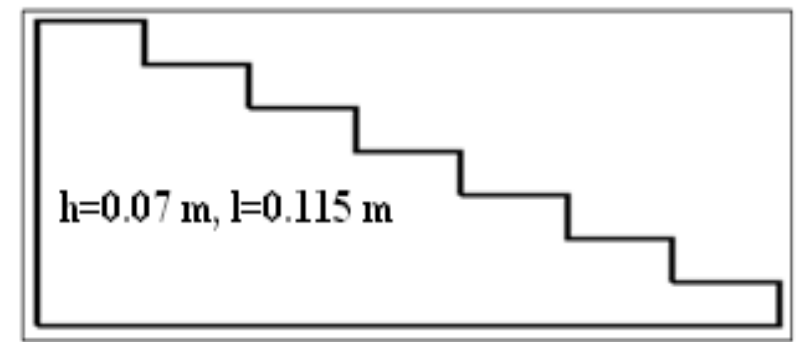

Fig.2 Model for number of steps 7

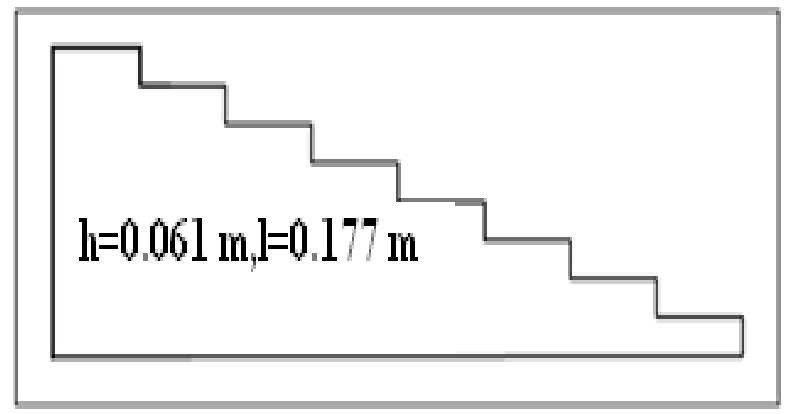

Fig. 3 Model for number of steps 8

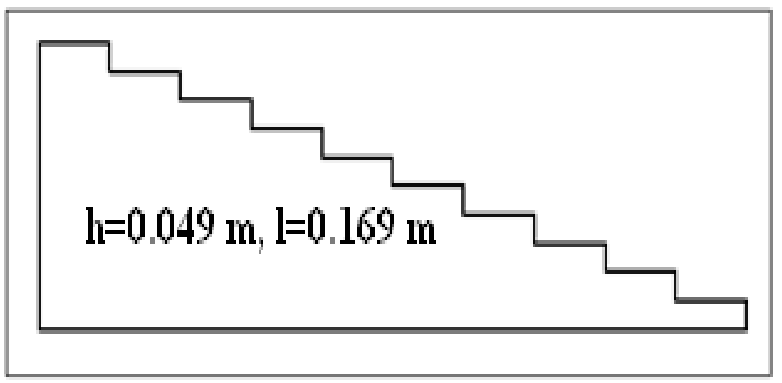

Fig. 3 Model for number of steps 10

\section{RESULT AND DISCUSSION}

A. Mean kinetic energy for different number of steps All the 24 cases were simulated using CFD software. The mean Kinetic energy were extracted for the each case. In this study two types of nappe flow is excepted i.e nappe flow with fully developed hydraulic jump and nappe flow with partial hydraulic jump. The plot of mean kinetic energy versus number of steps is presented in Figure No.4. Plot shows that for all eight discharges increasing the number of steps results in increase in mean kinetic energy. As the mean kinetic energy (residual energy) is inversely proportional to the energy dissipation, it can concluded that the increase in number of steps results in decrease in energy dissipation.

B. Mean kinetic energy for different discharges The plot of mean kinetic energy versus discharge for different number of steps $(7,8,10)$ is shown in Figure-5. It can be seen that for all three cases, increase in discharge results in increase in mean kinetic energy. Hence energy dissipation decreases with the increase in discharge. The energy dissipation very marginally with respect to number of steps when discharge is less than $0.002 \mathrm{~m}^{3} / \mathrm{s}$. 
C. Effect of $y_{c} / h$ on Mean kinetic energy

decrease in energy dissipation. When $\mathrm{y}_{\mathrm{c}} / \mathrm{h}<0.2$, less effect The plot of mean kinetic energy versus $y_{c} / h$ shown in on energy dissipation for all three number of steps were Figure-6. The plot shows that with increase in $\mathrm{y}_{\mathrm{c}} / \mathrm{h}$, the observed. mean kinetic energy increases for all cases, hence result in

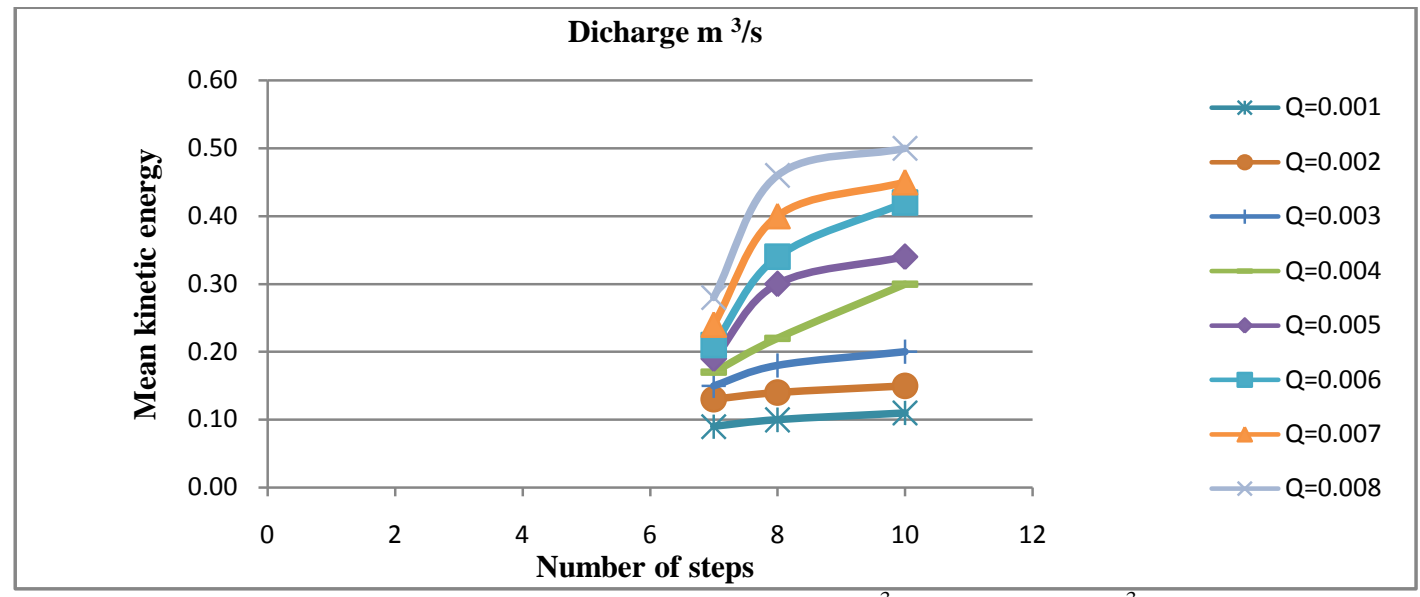

Fig. 4 Mean kinetic energy For $\mathrm{Q}=0.001 \mathrm{~m}^{3} / \mathrm{s}$ to $\mathrm{Q}=0.008 \mathrm{~m}^{3} / \mathrm{s}$

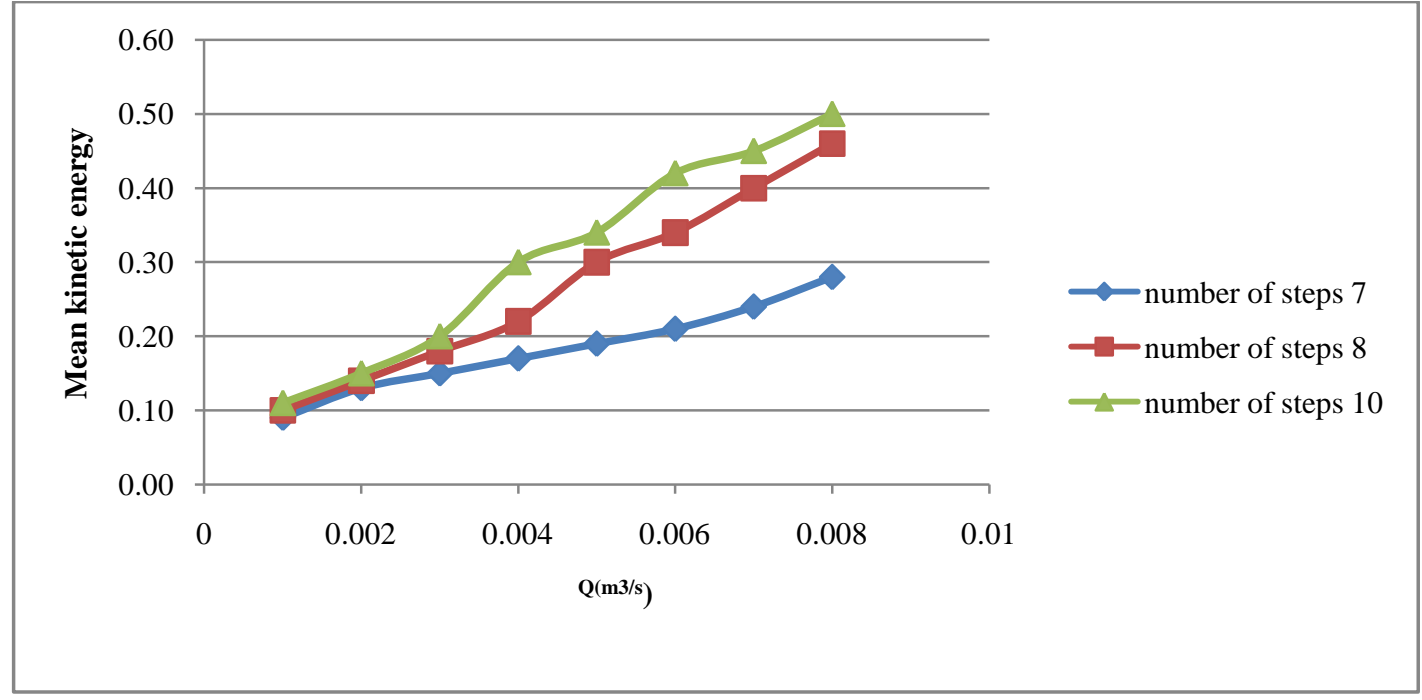

Fig.5 Mean kinetic energy for number of steps 7,8 and 10

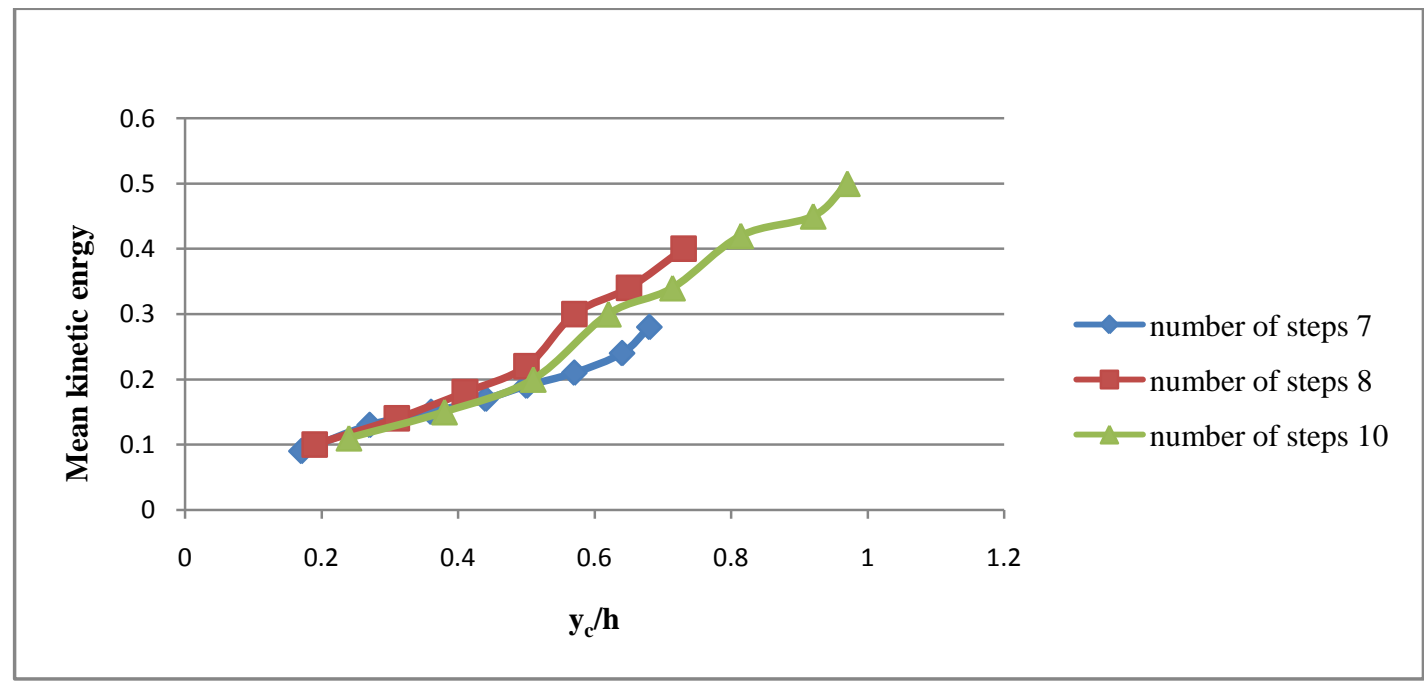

Fig. 6 Mean kinetic energy for different $y_{c} / h$ ratio 


\section{CONCLUSION}

This paper reports simulated flow results on the stepped spillway under nappe flow condition. In this study the effect of number of steps and discharge on energy dissipation were discussed. By increasing the number of steps and discharge, CFD simulation were carried out. The analysis of CFD simulations shows that:

a. Increase in number of steps result in decrease in energy dissipation.

b. Increase in discharge $\left(0.001 \mathrm{~m}^{3} / \mathrm{s}\right.$ to $\left.0.008 \mathrm{~m}^{3} / \mathrm{s}\right)$ for all number of steps result in decrease in energy dissipation.

c. There is marginal effect of number of steps on the energy dissipation when $\mathrm{y}_{\mathrm{c}} / \mathrm{h}<0.2$.

d. Increase in $\mathrm{y}_{\mathrm{c}} / \mathrm{h}$ ratio result in decrease in energy dissipation.

e. At $\mathrm{y}_{\mathrm{c}} / \mathrm{h}=0.97$, nappe flow change to skimming flow regime.

\section{REFERENCES}

[1] Ali Heidari , Poria Ghassemi (2014), “Evaluation of step's slope on energy dissipation in stepped spillway".International Journal Of Engineering \&Technology.3(4), pp.501-505.

[2] Barani G.A.,Rahnama M.B. and Sohrabipoor N. ( 2005), "Investigation of Flow Energy Dissipation over Different Stepped Spillways". American Journal of Applied Sciences2 (6) , pp. 11011105.

[3] Chafi C., Hazzab A. ,Seddini A. (2010), "Study Of Flow \&Energy Dissipation In Stepped Spillways". Jordan Journal Of Civil Engineering,Vol.4, pp.1-11.

[4] Chanson H.( 1993) , "Hydraulics Of Stepped Spillways \&Cascades ".ASCE Vol.126,No.9,pp. 636-637.

[5] Chamani M.R. and Rajaratnam N. (1994), "Jet flow on stepped spillways". Journal of hydraulic engineering, 120(2), pp. 254-259.

[6] Christodoulou G. C. (1993), "Energy dissipations on stepped spillways, Journal of hydraulic engineering", Vol.119, pp. 644-650.

[7] Hunt S. L. , Kadavy K. C. (2010), "Energy Dissipation On Flat-Sloped Stepped Spillways ".American Society Of Agricultural \&Biological ,Vol.53(1),pp.103-109 .

[8] Jean ,Chatila G. , Bassam R. Jurdi(2014), “ stepped spillway as a energy dissipator '.Canadian Water Resources Journal, pp.147158.

[9] Khatsuria R.M.(2005) "Hydarulics of Spillways And Energy Dissipators "., Marcel Dekker,New York ,NY 10016, U.S.A

[10] Rasul M. Khalaf, Raad H. Irzooki , Saleh J.S. Shareef (2014) , “ Flow Characteristics and energy dissipation over Traditional and stepped spillway with semicircular crest ". International Journal of Civil \& Environmental Engineering, Vol. 14, pp. 13-25.

[11] Rao P.V.and Rao P.L. (1995), "Jet flow on stepped spillway". ASCE Vol.121, pp.441-445

[12] Roshan R., Azamathulla, H. Md., Marosi, M., Sarkardeh, H., Pahlavan, H., Ab Ghani, A., (2010),"Hydraulics Of Stepped Spillways With different number of steps ". Journal Of Dams \& Reservoir, Vol.20,No.3,pp. 131-136.

[13] Stefan Felder and Hubert chanson (2011), "Energy Dissipation down a Stepped Spillway with No uniform Step Heights". Journal Of Hydraulic Engineering ASCE, Vol. 137 ,pp.1543-1548.

[14] Tatewar S.P. , Ingle R. N. , Porey P.D.(1999), " Nappe flow on inclined stepped spillways ". Journal of Institution of engineers, pp.175-179.

[15] Uones Khademi \& Mohammad Shirvani (2014), "Hydrodynamic modeling of flow over different type of stepped spillway". Indian Journal of fundamental \& applied life sciences, Vol.4, pp 12901296.

\section{BIOGRAPHY}

Dr. L.G. Patil received the BE in Civil Engineering from Karnataka University, M.Tech in Hydraulics and Water Resources Engineering from NIT , Suratkal and Ph.D in Environmental Hydraulics from IITB , Mumbai. Currently working as Associate Professor in Department of Civil Engineering, SGGSIE\&T, Nanded.

Jadhav Sarika S. received the BE in Civil Engineering from SRTMU University and pursuing M.Tech in Water Management from SGGSIE\&T, Nanded.

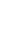

